\title{
Thermal Insulation Materials From Sapropel And Hemp Shives (Cannabis Sativa L.)
}

\author{
Staņislavs Pleikšnis, Ilze Dovgiallo \\ Rezeknes Augstskola, Faculty of Engineering, Environmental Technology Transfer \\ Address: Atbrivosanas aleja 76, Rezekne, LV-4601, Latvia, \\ e-mail: stanislavs.pleiksnis@ru.lv,ilze.dovgiallo@inbox.lv
}

\begin{abstract}
In Latvia, sapropel is an organic lake sediment that is formed from the remains of aquatic animals and aquatic plants, containing mineral particles (sand, clay, calcium carbonate and other compounds). Hemp is a rapidly growing multi - functional energy plant. Hemp seeds and fibre have a very high value on the world market, but in the world when processing hemp, shives of hemp remain as waste. The solution is found in the resources available in Latvia to use them for increasing energy efficiency as a thermal insulation material. The aim of the research is to find out the properties of the thermal conductivity for lightweight concrete from sapropel and hemp shives to be used as a thermal insulation material. An application with the number P-12-200 is submitted to the LR Board of Patents on 20.12.2012. for granting of a patent to the "Hemp shives and sapropel for thermal insulation of buildings".
\end{abstract}

Keywords : natural raw materials, hemp shives, sapropel, thermal conductivity, FOX600.

\section{INTRODUCTION}

Increasing of energy consumption in all economics sectors, as well as stocks decrease of fossil fuels, environmental pollution and climate changes - global warming, interest in the use of renewable energy resources in power generation and the use of new ecological building materials in construction and insulate old buildings.

The consumption of primary energy resources continuously increases all over the world. Now natural gas or oil is primary energy resources in Latvia and in many other countries and a sharp reduction of nonrenewable mineral resources.

Using just a natural, renewable and efficient materials reduce the energy consumption of building heating and non-recyclable debris does not.

The EU, using various tools, actively tries to solve this problem. One of strategic activity direction is to increase the energy efficiency and determination of the standards for existing and planned buildings.

The results of projects implemented in European countries and Latvia show that integrated insulation of buildings can reduce the consumption of heating energy by $40-60 \%$ in comparison with initial consumption.

Living in Latvians climate conditions, you have to take into consideration high energy consumption for heating the buildings. Heating season lasts for 7 months a year in average.

The best effect of energy consumption reduction can be achieved by integrated solutions that include improvement of all weak phases of construction, thus increasing the energy efficiency of buildings.

In order achieve the maximal effect it is important to use new ecological building materials. It is important to balance the indicators of the energy efficiency of building material and consumed energy during production process of this building material. For the solution of this problem the use of local raw materials is topical in the production of building materials.

Therefore, the development and testing of new, innovative and natural building material - sapropel and hemp shives lightweight concrete.

Using sapropel construction are handled in Latvian overgrown lake treatment. Other hand, cannabis grow, absorb $\mathrm{CO}_{2}$ and give off $\mathrm{O}_{2}$, thereby directly tied hemp $\mathrm{CO}_{2}$ does not escape into the atmosphere. When growing hemp does not require pesticides in plant disease-and pest-natural, which would increase the production costs. Therefore, combining these two Latvian available raw materials, will be able to solve the problem of Latvian energy issue.

\section{MATERIALS AND METHODS}

\section{Materials}

For the scientific research, natural raw materials were obtained from a variety of local businesses. Sapropel was obtained from Ubogova Lake in the parish of Mākonkkalns, while hemp shives - from the Preili flax pre-processing shop. The lightweight concrete samples from sapropel and hemp shives for the determination of the thermal insulation were manufactured and tested during the period from October 2012 to April 2013 in the chemistry laboratory of the Faculty of Engineering of the Higher School of Rezekne and the testing laboratory of building materials of the Riga Technical University.

In the chemistry laboratory of the Faculty of Engineering of the Higher School of Rezekne, the samples were prepared for the experiment, which was carried out in the testing laboratory of building materials of the Riga Technical University with the thermal flow meter Fox 600. In total, six 
measurements were made, in which six compound mixes were checked.

Six different samples of ingredients in the form of plates were made in the laboratory: $350 \times 350 \times 50$, one ingredient of which was sapropel $(5,66 \%$ of sapropel, 94,34\% of water) and the other constant ingredient was hemp shives. The water was used for mixing the ingredients. The mixture ratio (by weight) was as follows:
a) $2: 1$;
b) $2.5: 1$;
c) $3: 1$;
d) $3.5: 1$;
e) $4: 1$;
f) $5: 1$.

The mixture of raw materials was laid by layers in pre-made moulds, each layer firmly pressing (by hands). When the moulds were filled in, the mixture from the top was pressed so as the mass would remain dense. In the following way, each sample was processed.

The samples were initially hardened in the conditions of the chemistry laboratory of the Faculty of Engineering of the Higher School of Rezekne at + $20 \pm 2{ }^{0} \mathrm{C}$ for the duration of 3-5 days, depending on the quantity of the binder substance, then the samples were removed from the mould. After removal from the moulds, the samples were continued to dry and harden in the laboratory conditions for 3-4 weeks to a complete drying (ref. Figure 1).

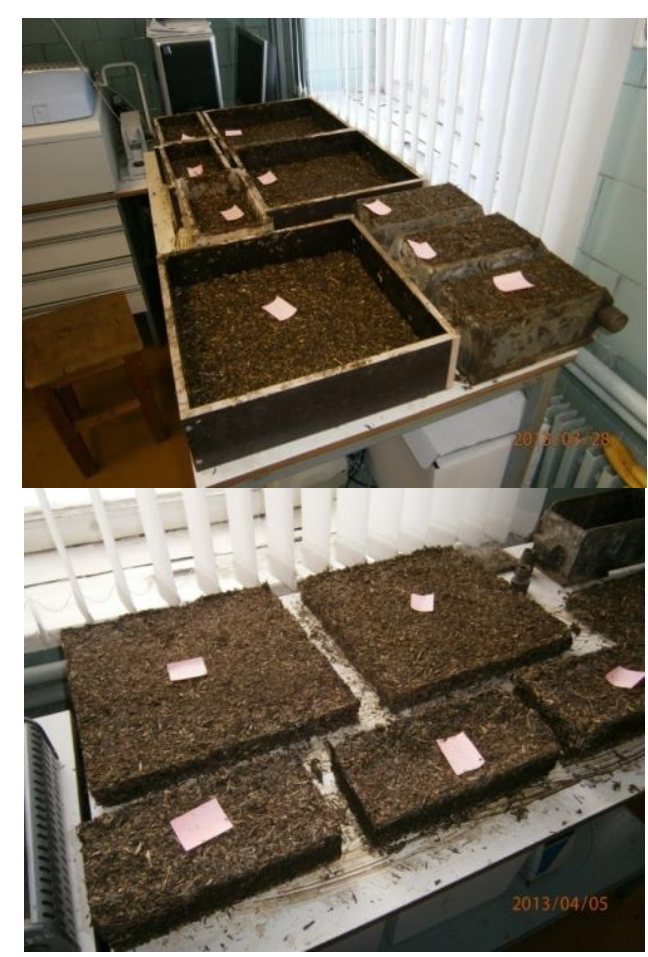

Figure 1. The drying process of the lightweight concrete of the new building material from sapropel and hemp shives

\section{Methods}

In the testing laboratory of building materials of the Riga Technical University, for the determination of the coefficient of thermal conductivity in the samples there was used Laser Comp FOX600 series instrument.

The general principle of the FOX heat flow meter instruments is based on onedimensional Fourier-Biot law:

$$
q=-\lambda\left(\frac{d T}{d x}\right)
$$

where

$\mathrm{q}$ is heat flux $(\mathrm{W} / \mathrm{m} 2)$ flowing through the sample,

$\lambda$ is its thermal conductivity (W m-1 K-1),

$\mathrm{dT} / \mathrm{dx}$ is temperature gradient $(\mathrm{K} \mathrm{m}-1)$ on the isothermal flat surface.

If a flat sample is placed between two flat isothermal plates maintained at two different temperatures, and a uniform one-dimensional temperature field has been stabilized, the temperature field in the sample should be uniform within all the sample's volume (size of the plates is supposed to be much larger than thickness of the sample). The temperature gradient can be determined by measurements of the difference between temperatures of the hot and cold plates $(\Delta \mathrm{T}=$ Thot $-\mathrm{Tcold})$ and thickness of the sample $\Delta x$, because in this case average temperature gradient $\mathrm{dT} / \mathrm{dx}$ is equal to $\Delta \mathrm{T} / \Delta \mathrm{x}$.

Before starting tests (i.e. measurements of thermal conductivity) of a sample with unknown thermal conductivity, the heat flow meter instrument must be calibrated using some certified sample (standard) having reliable known values of thermal conductivity $\lambda$ cal (T).

Electric signal from the transducer $\mathrm{Q}(\mu \mathrm{V})$ is proportional to the heat flux q:

$q=\frac{\lambda\left(T_{\text {cal }}\right) \Delta T_{\text {cal }}}{\Delta x_{\text {cal }}}=S_{\text {cal }}\left(T_{\text {cal }}\right) Q$

Because physical properties of the transducer change with temperature, temperature calibration of the instrument using the calibration standard is always necessary to get the temperature dependent calibration factor Scal (T). Dimension of the calibration factor is $\mathrm{W} \mathrm{m}-2 \mu \mathrm{V}-1$ or $\mathrm{W} \mathrm{m}-2 \mathrm{mV}-1$. A reciprocal value (sensitivity of the heat flow meter) is used in some laboratories. Each of the two transducers has its own temperature, so the calibration factors should be referred to the transducers' actual temperatures. Two separate sets of the calibration factors are measured during the calibration run.

The calibration factors Scal (T) are the instrument's characteristics. They are used

for thermal conductivity calculation during the test run:

$$
\lambda_{\text {test }}=S_{\text {cal }}\left(T_{\text {test }}\right) Q \Delta x_{\text {test }} / \Delta x_{\text {test }}
$$

Similarly, because each plate has its own temperature the calibration factors should be 
calculated for plate's actual temperature. Average of two thermal conductivity values is a final result of thermal conductivity test.

Typical value of thermal diffusivity $a=\lambda /(\mathrm{Cp} \rho)$ of thermal insulation materials is about (4-7) 10-7 m2s-1 $(\mathrm{Cp} \rho)$ is volumetric specific heat, $\mathrm{Cp}$ is specific heat at constant pressure, $\rho$ is density). Fourier number (dimensionless thermal similarity parameter used in studying heat flow problems) Fo $=$ at $/(\Delta x / 2) 2$ is about 9-16 per hour for 1" $(25.4 \mathrm{~mm})$ thick sample. So, it takes a fairly long time (not less than 0.5 hour for 1 "thick sample) to reach full temperature equilibrium to have Fo $>>1$. And 4"-thick sample needs about 16 times more time (about 8 hours) to reach the same temperature equilibrium. Experimental check showed that average value of two heat flow meters signals reaches equilibrium several times faster than their individual values. So, practically the duration of tests is shorter, because thermal conductivity value is calculated using the average value of the signal.

\section{RESULTS AND DISCUSSION}

The experiment resulted in a new composite material - a lightweight concrete from gyttja -clay and hemp shives. In order to ensure the operability of this material as a material of thermal insulation, its density and the conductivity $\lambda$ were determined. The density of the material is in the range of 165,25 to $146,01 \mathrm{~kg} / \mathrm{m}^{3}$ (the average density $\rho=152,75 \mathrm{~kg} / \mathrm{m}^{3}$ ) (ref. Figure 2). The density $\rho\left(\mathrm{kg} / \mathrm{m}^{3}\right)$ for the samples was determined according to the formula:

$\rho=\frac{m}{V^{3}}$

where $\mathrm{m}$ - is the mass of the sample and $\mathrm{V}-$ the volume of the sample.

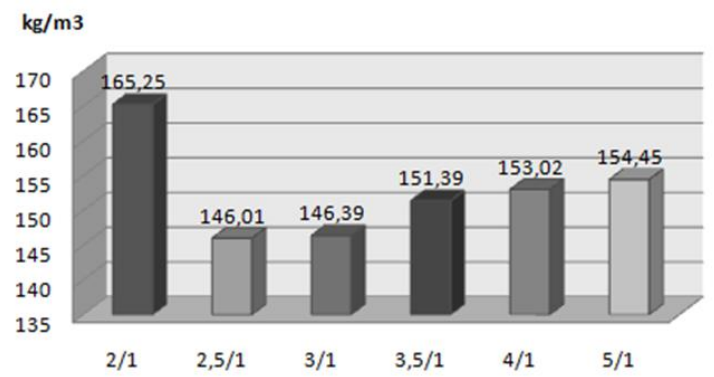

Figure 2 . The sample density $\rho$ depending on the composition ratio

Thermal conductivity was determined by the thermal flow meter Fox 600 (ref. Figure 3). The sample was placed in a device for several hours, after completion of the measurement the device showed the thermal conduction coefficient $\lambda(\mathrm{w} / \mathrm{mK})$. Coefficient $\lambda$ of the thermal conductivity of the material, by changing proportions of sapropel in the samples, did not change.

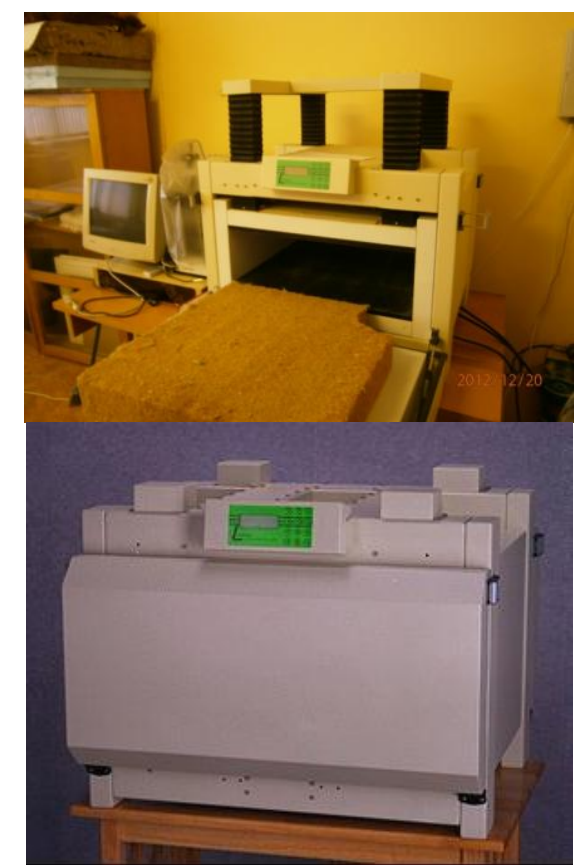

Figure 3. LaserComp FOX600 in the testing laboratory of building materials of the Riga Technical University.

Practically, the coefficient $\lambda$ of the thermal conductivity can be considered a constant value, as the average thermal conductivity $\lambda$ is $0.05516 \pm 0.005$ w/mK. (Ref. Figure 4).

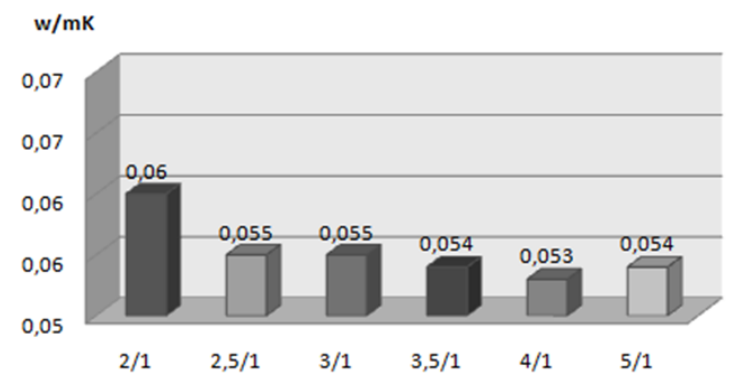

Figure 4 . The sample thermal conductivity $\lambda$ depending on the composition ratio

The findings were summarized in the summary table

TABLE 1

DENSITY/ /THERMAL CONDUCTIVITY RATIO TABLE

\begin{tabular}{|l|l|l|l|}
\hline \multicolumn{2}{|c|}{} & \multicolumn{2}{|l|}{ Samples $350 \times 350 \times 50 \mathrm{~mm}$} \\
\hline $\begin{array}{l}\text { Composition } \\
\text { number }\end{array}$ & $\begin{array}{l}\text { Ratio } \\
\text { hemp/ } \\
\text { sapropel }\end{array}$ & $\begin{array}{l}\text { Density } \\
\mathrm{kg} / \mathrm{m}^{3}\end{array}$ & $\begin{array}{l}\text { Thermal } \\
\text { conductivity } \\
\lambda(\mathrm{w} / \mathrm{mK})\end{array}$ \\
\hline 1 & $2: 1$ & 165,25 & 0.060 \\
\hline 2 & $2,5: 1$ & 146,01 & 0.055 \\
\hline 3 & $3: 1$ & 146,39 & 0.055 \\
\hline 4 & $3,5: 1$ & 151,39 & 0.054 \\
\hline 5 & $4: 1$ & 153,02 & 0.053 \\
\hline 6 & $5: 1$ & 154,45 & 0.054 \\
\hline
\end{tabular}




\section{CONCLUSIONS}

According to the results obtained (Figure 2), a certain correlation can be evidenced that the density of the new composite material is increased by increasing the quantity of sapropel in the sample. The first sample does not fit in this line and it could be explained by the fact that the sample was more pressed. It also slightly affected the thermal conductivity $\lambda$ of the sample (Table 1). In other samples ranging from different compositions of sapropel and hemp, conductivity $\lambda$ remains almost unchanged (Table 1), so in the resulting composite material, thesapropel quantity affects the thermal properties in the least.

Conductivity of natural thermal insulation materials is not much inferior to the artificial ones, but the energy consumption of $1 \mathrm{~m}^{3}$ for production of the material is much lower (Figure 5).

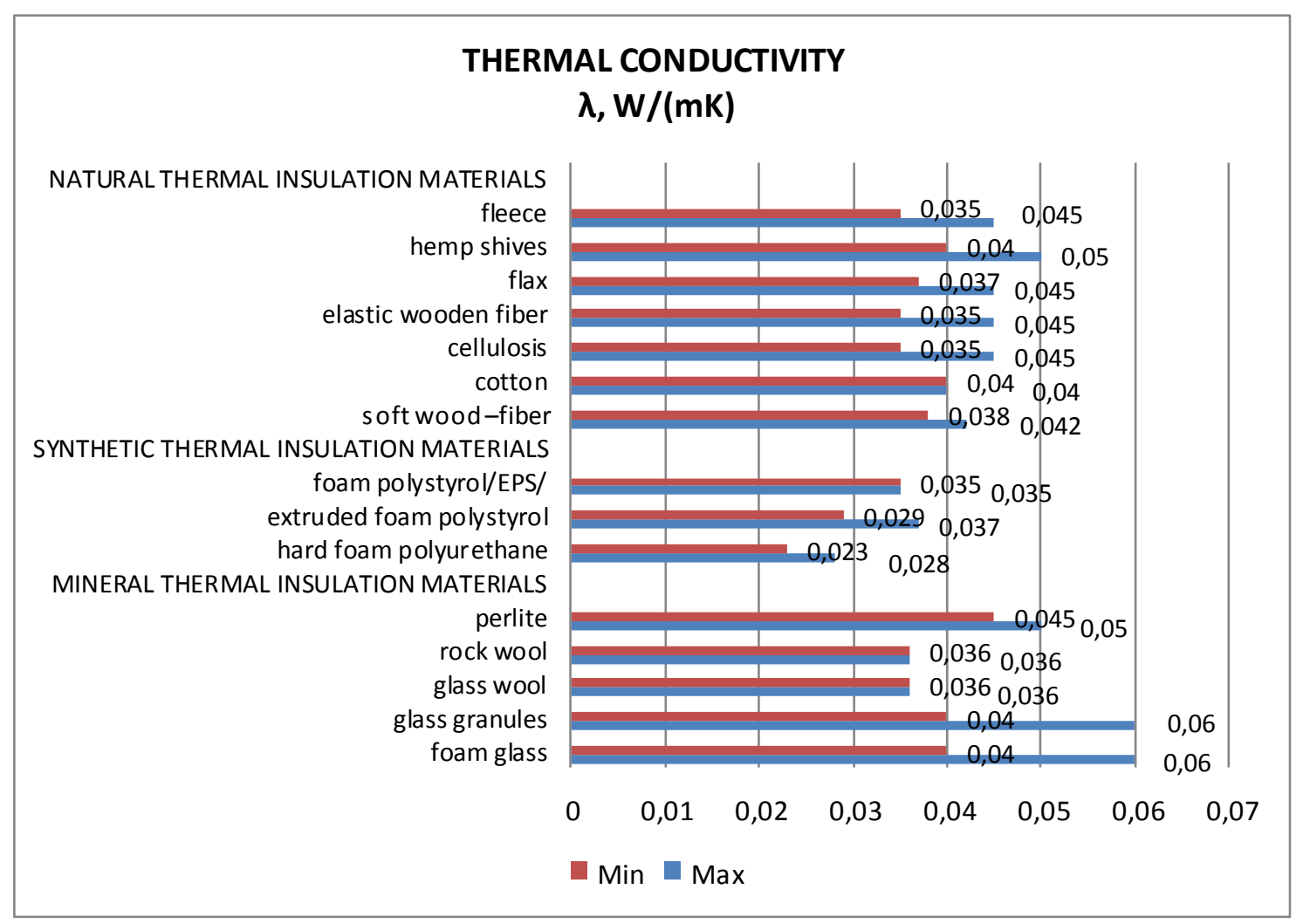

Figure 5. Thermal conductivity of different insulation materials

If you compare the natural thermal insulation material with synthetic or mineral materials for thermal insulation, hemp shives have very good thermal conduction properties (ref. Figure 5), but using the same ones, they also have negative aspects:

1) Not hold together in the prescribed form;

2) Dusty;

3) Not convenient to transport;

4) When insulating a building, you have to create a rigid body structure;

5) Permanent moulds must be used.

While using these two in Latvia available natural materials, these issues do not arise.

The buildings, constructed from hemp shives and sapropel lightweight concrete, have much less environmental impact than the conventional ones: less energy consumption of the raw material extraction, virtually no construction waste and the thermal insulation properties correspond to the modern requirements.
Working with such material does not pose a risk to the environment and human health.

It is essential that the natural thermal insulation materials, after rebuilding of the building or dismantling, get into nature, decompose and cause no pollution. In contrast, the chemical insulation foam or other artificial materials, naturally decomposing, are causing serious chemical pollution.

\section{REFERENCES}

[1] Borodinnecs A., Krēslinšs A. RTU recommendations Construction Standard LBN 002-01 for use in the design and construction of buildings, Riga, 2007th

[2] Appene I.; Hemp insulation or kanaizols http://www.em.gov.lv/images/modules/items/

[3] FOX600 and FOX800 Series Instruments Manual THEORY OF THE METHOD

[4] Insulation materials; http://www.ergliarods.lv/sites/ default/files/Videi_draudzigi_izolacijas_materiali.pdf

[5] Nierobis L. Thermal insulation; http://www.waermedaemmstoffe.com/

[6] Allin, S. (2005). Building with Hemp, Seed Press, Rusheens, Kenmare, Co. Kerry, Ireland. 
[7] Lācis A. Sapropel Latvian, State Geological Survey

[8] Dementev V. A.Removal of organic sediments from reservoirs and lakes and their processing https://springerlink3.metapress.com/content/358g6413623237 33/resource-

secured/?target=fulltext.pdf\&sid=hsk0h341jho04vvresamjwsl $\&$ sh=www.springerlink.com

[9] Elfordy S., Lucas F., Tancret F., Scudeller Y., Goudet L. (2008). Mechanical and thermal properties of lime and hemp concrete ("'hempcrete") manufactured by a projection process. Construction and Building Materials.
[10] Lukss J.; Insulation effects and problematic; magazine "Manager"

http://www.em.gov.lv/images/modules/items/parvaldnieks_bu vniec_kvalit_diskus_parvald.pdf (15.01.2013.)

[11] Liepa L., Grūbe G.; Without insulation will not do anymore; magazine professionals 'My

http://mmp.multiprese.lv/index.php?n=588\&a=4766 